\title{
Optical coherence tomography-guided versus angiography-guided implantation of everolimus- -eluting bioresorbable vascular scaffolds: Comparison of coverage, apposition and clinical outcome. The ALSTER-OCT ABSORB registry
}

\author{
Christian-Hendrik Heeger, ${ }^{1,2}$, Anne-Sophie Schedifka ${ }^{1}$, Felix Meincke ${ }^{1}$, \\ Tobias Spangenberg ${ }^{1}$, Hendrick Wienemann ${ }^{1}$, Felix Kreidel ${ }^{1}$, \\ Karl-Heinz Kuck ${ }^{1}$, Alexander Ghanem ${ }^{1}$, Martin W. Bergmann ${ }^{3}$ \\ ${ }^{1}$ Department of Cardiology, Asklepios Clinic St. Georg, Hamburg, Germany \\ ${ }^{2}$ Department of Cardiology, University of Luebeck, Germany \\ ${ }^{3}$ Cardiologicum, Hamburg, Germany
}

\begin{abstract}
Background: Suboptimal implantation of everolimus-eluting bioresorbable vascular scaffolds (EE-BVS) leading to strut malapposition and lack of neointima coverage has been hypothesized to be linked to late BVS-thrombosis. Optical coherence tomography (OCT) allows assessing subtle differences in BVS-healing. We aimed to link 6-months OCT-data on EE-BVS coverage and malapposition to implantation technique and clinical outcome.

Methods: Twenty-nine consecutive EE-BVS-patients were included. EE-BVS-implantation was guided by angiography in the first 17 patients (group 1). Vessel sizing prior to implantation and implantation result was assessed by OCT in the 12 following patients (group 2). EE-BVS-implantation was performed in both groups with adequate lesion preparation, sizing and systematic high-pressure post-dilatation. All patients received 6-months invasive control including OCT-analysis and clinical follow-up for 2 years.

Results: The rate of uncovered struts was group 1: $10.8 \pm 10.0 \%$; group 2: $10.6 \pm 8.2 \%, p=0.934$. Target lesion failure due to BVS-thrombosis occurred in 2/17 patients at 9 and 18 months (11.8\%, group 1), and no patients in group 2 ( $p=0.218)$.

Conclusions: Optical coherence tomography analysis at 6-months following EE-BVS-implantation finds almost $90 \%$ of struts to be covered. No difference between OCT vs. angiography-guided EE-BVS-implantation was observed. OCT at 6-months was not able to predict late BVS-thrombosis of EE-BVS. (Cardiol J 2018; 25, 4: 459-469)
\end{abstract}

Key words: optical coherence tomography, bioabsorbable vascular scaffolds, vascular healing

\section{Introduction}

Bioresorbable vascular scaffolds (BVS) have been designed to improve the limitations of con- ventional percutaneous coronary intervention (PCI) with drug-eluting stents (DES), namely to restore vessel vasomotion and to minimize neoarteriosclerosis [1]. The everolimus-eluting BVS

Address for correspondence: Christian-Hendrik Heeger, MD, Asklepios Clinic St. Georg, Department of Cardiology, Lohmühlenstraße 520099 Hamburg, Germany, tel: +49-40-181885-4400, fax: +49-40-181885-4444, e-mail: christian.heeger@gmx.net

Received: 02.11.2018 Accepted: 27.12.2017 
(EE-BVS, Abbott Vascular, Santa Clara, USA) has been studied in randomized trials compared to EE-DES. Although initial data suggested noninferiority at 12-months [1], the latest registries and meta-analysis found an increased risk of BVS-thrombosis [2-5]. Suboptimal BVS-implantation resulting in BVS-underexpansion and malapposition was suggested to be causal [6-8]. Guidance by intravascular imaging in sizing and optimising BVS-implantation is hypothesized to solve these issues. A BVS specific implantation protocol including lesion preparation, accurate vessel sizing and mandatory post-dilation was implemented after the first observations of scaffold thrombosis when the device first came into use in routine PCI in Germany back in 2013 [6, 9]. Intravascular imaging with optical coherence tomography (OCT) is considered to allow optimal BVS-size selection, strut apposition and BVS-expansion [6]. Recently published data found OCT to detect BVS-malapposition and underexpansion despite angiographic determined success in over $25 \%$ of implantations [10]. Furthermore, preliminary findings of OCT-based guidance for DES-implantation have been shown to improve clinical outcomes [11]. Aside from guidance during PCI, OCT has become a powerful tool to evaluate DES and BVS-coverage and apposition in follow-up examinations. Quantitative data from follow-up OCT-imaging has been proposed as surrogate parameters for stent performance linked to clinical outcome [12-16]. The present ALSTER-OCT ABSORB registry (AskLepios ST. GEoRg's hospital-Optical Coherence Tomography for follow-up of ABSORBable vascular scaffolds) analyzed OCT-data regarding BVS-coverage, neointimal thickness and apposition at 6 months following EE-BVS-implantation. These data were linked to implantation technique (angiography-guided vs. OCT-guided) and 2-year clinical outcome.

\section{Methods}

\section{Design and patient enrolment}

The ALSTER-OCT ABSORB registry (Fig. 1) was a prospective, all-comers, single-center registry to study EE-BVS healing characteristics by OCT at 6 months subsequent to implantation. Results were stratified for implantation technique regarding OCT- vs. angiography-guided EE-BVS-implantation. The registry also tried to identify EE-BVS-healing patterns that would have possibly allowed to predict 2-year clinical outcome. Between $01 / 2014$ and 09/2015 surveillance angiography with
OCT was performed in 29 patients. Patients with complex lesions (ostial stenosis, stenosis of the left main trunk, lesions $\geq 10 \mathrm{~mm}$ length in vessels $\leq 3.5 \mathrm{~mm}$ diameter) treated with EE-BVS were eligible. The lesion type assessments were performed according to latest ACC/AHA definitions [17]. This registry conforms to the guiding principles of the Declaration of Helsinki of 2008 and was approved by the local institutional review board. Written informed consent was obtained from all patients.

\section{PCI and BVS implantation}

All interventions and choice of antithrombotic therapy was performed according to current PCI guidelines [18]. Intravenous heparin $100 \mathrm{IU} / \mathrm{kg}$ was given to maintain the activated clotting time $>250 \mathrm{~s}$. Balloon predilation was performed in all patients. BVS-implantation at a pressure not exceeding the burst pressure rate was mandatory. If post-dilation was performed, a non-compliant balloon was used. Angiographic success was defined as diameter stenosis $<30 \%$ with thrombolysis in myocardial infarction (TIMI) 3 flow by visual assessment [10]. After evidence of angiographic success no further evaluation was performed in the first 17 consecutive patients (group 1: angiography-guided EE-BVS-implantation).

\section{Periprocedural OCT-imaging}

In patients of group 2 (OCT-guided EE-BVS-implantation) initial predilatation was performed to allow OCT-imaging of the lesions, to determine proximal and distal reference diameters, position of side branches, and further lesion characteristics. Further predilatation was undertaken to within $0.5 \mathrm{~mm}$ of the reference vessel diameter. The average diameter of the target zone lumen was determined as reference for the BVS diameter. If BVS-underexpansion or malapposition was identified by angiography, further post-dilatation was undertaken using non-compliant balloons until angiographic success was achieved. A further OCT-analysis was performed afterwards to assess BVS-expansion, apposition and dissection. On the basis of this OCT-analysis, further BVS-optimisation was performed according to the following definitions: BVS-underexpansion was defined as minimum BVS area $<80 \%$ of the mean proximal and distal reference lumen areas [10]. BVS-malapposition was defined as incomplete BVS-apposition area delineated by the abluminal side of the frame border of the malapposed strut and the endoluminal contour of the vessel wall $[10,19]$. A representative case is presented in Figure 2. 


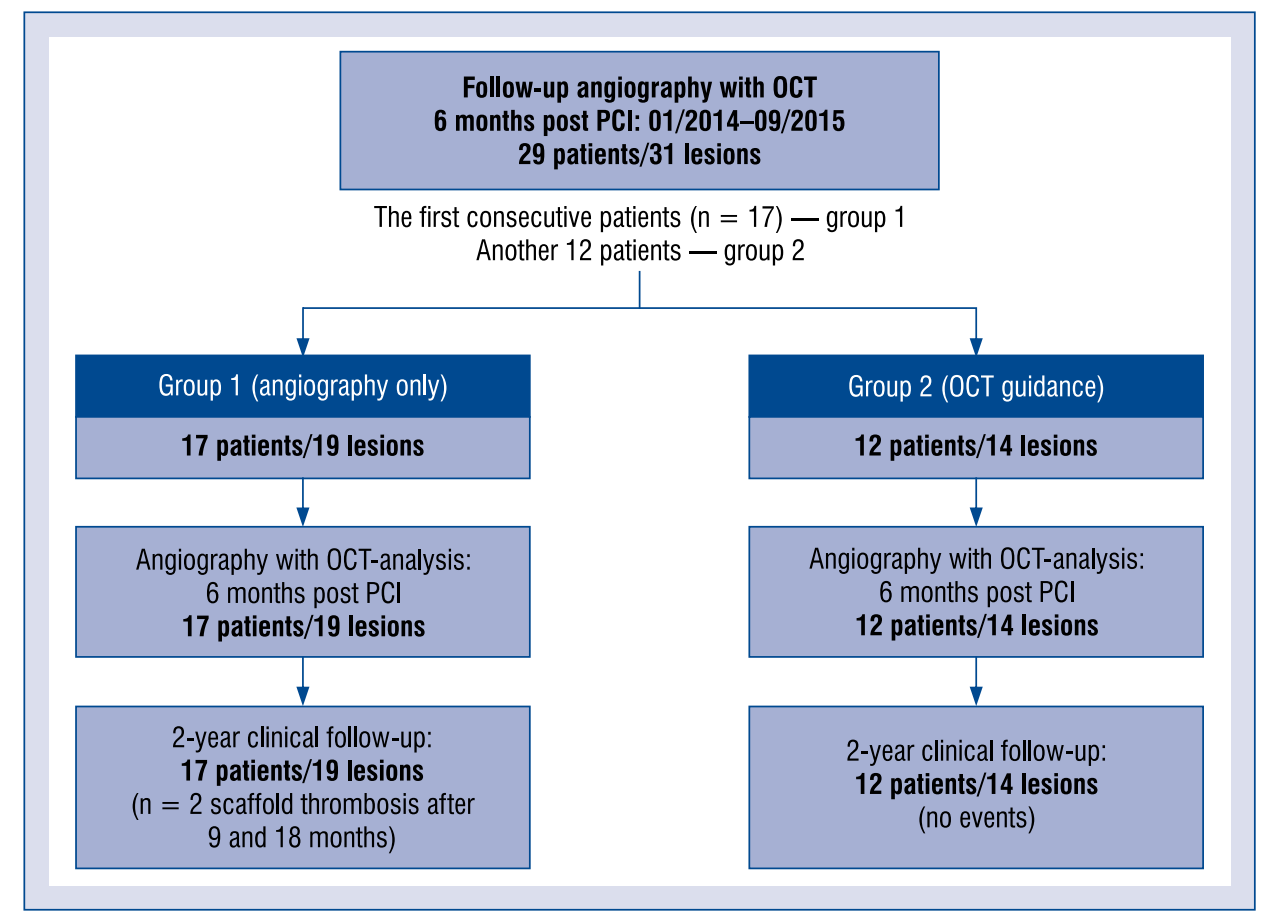

Figure 1. ALSTER-OCT ABSORB registry — flow chart of patients included in this prospective registry. OCT — optical coherence tomography; $\mathrm{PCl}$ - percutaneous coronary intervention.

\section{OCT-imaging and analysis at follow-up}

Frequency domain OCT-pullbacks were performed according to guidelines and obtained with the Ilumien system (St. Jude Medical, Saint Paul, USA) [13, 14, 20, 21]. As recently described acquired data was analyzed at the LightLab Imaging OCT-offline workstation (OCT-system software B.0.1, LightLab) [13, 14]. Image assessments were performed in every $5^{\text {th }}$ cross-section. All crosssections were screened for quality and excluded from analysis if any portion of the image off of the screen, the image was of poor quality caused by residual blood, sew-up artefact, or reverberation. Struts located at the ostium of coronary artery side branches, are donated as non-apposed sidebranch struts and exclude from the analysis. According to previously described methods BVS were analyzed strut-by-strut and qualified as the following: Embedded covered struts: covered by tissue with at least $50 \%$ of the strut boundary below the level of the luminal surface. Protruding covered struts: covered by tissue and with the strut boundary located above the level of the luminal surface. Uncovered apposed struts: for those not covered by tissue but abutting the vessel wall and final uncovered and malapposed struts: for those not covered by tissue and not abutting the vessel wall. If neointimal tissue was observed, its average thickness was measured. It was measured in every strut between abluminal site of the strut core and the lumen. Since the strut thickness of EE-BVS is $150 \mu \mathrm{m}$, the strut was considered as covered whenever the thickness of the coverage was above this threshold value $[19,22,23]$. The strut core area was measured within the area of the strut. Two independent expert observers (blinded to the clinical and procedural characteristics) did the OCT-analysis. To determine reproducibility, measurements of 5 randomly chosen patients $(\mathrm{n}=631$ struts) were repeated and intra- and inter-observer reproducibility were calculated [12].

\section{Clinical follow-up}

Target-lesion-failure was defined as a composite of cardiac death, target-vessel myocardial infarction (MI), ischemia driven target-lesion-revascularization (TLR) within 2 years [13, 14, 24]. Target-vessel-revascularisation (TVR) was defined as non-target lesion revascularization of the target vessel $[13,14,25]$. The composite of cardiac death, MI and ischemia driven TLR within 2 years was considered as major adverse cardiac events $[13,14,26]$. 


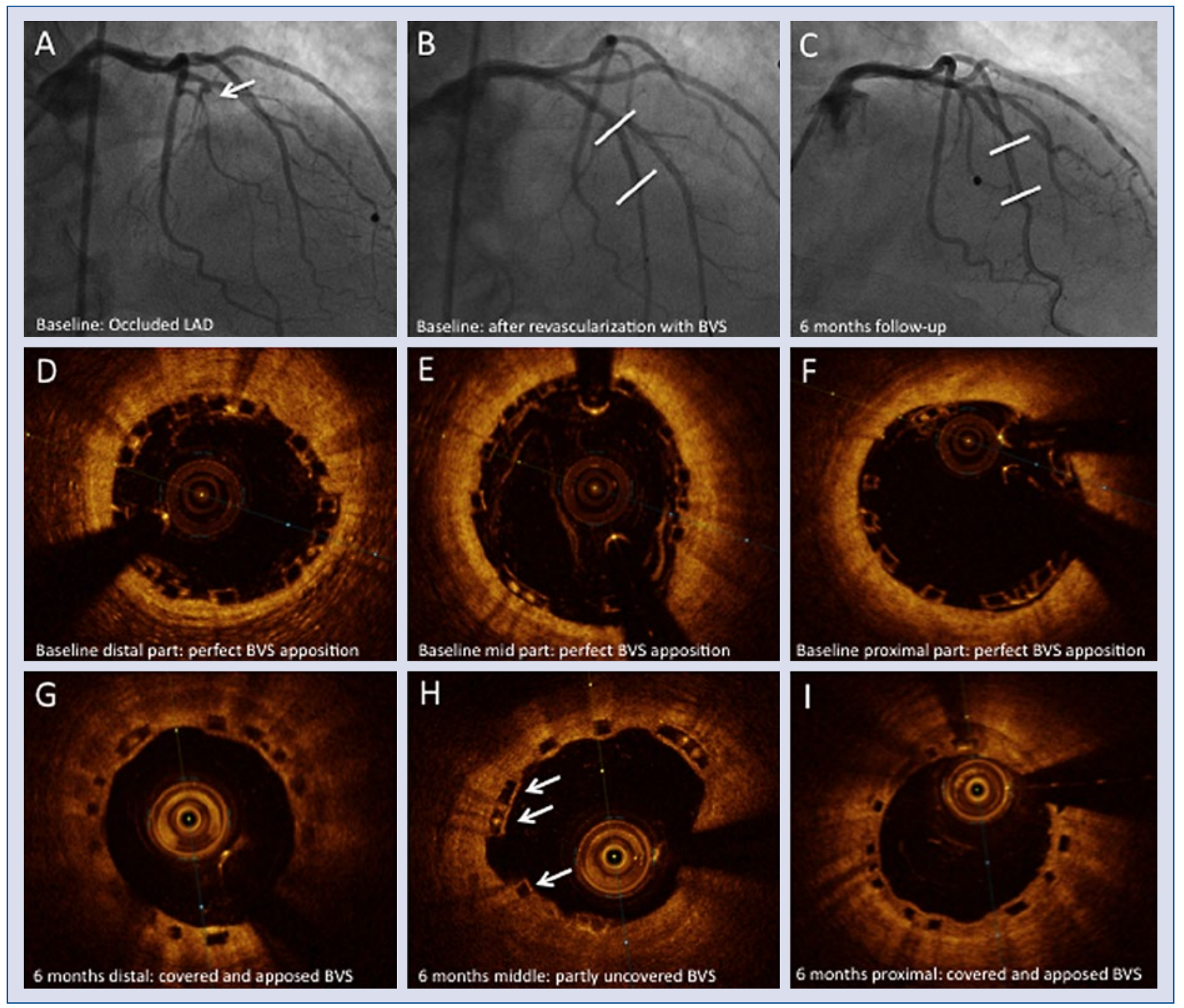

Figure 2. Representative images: optical coherence tomography (OCT)-guided bioresorbable vascular scaffold (BVS)-implantation; A. Baseline coronary angiography with occlusion of the proximal right coronary artery (RCA) resulting in BVS implantation; B. Angiography after implantation of a BVS (Absorb $3.0 \times 28 \mathrm{~mm}$, BVS is marked by white bars); C. Angiography at 6 months follow-up; D, E, F. OCT images at baseline after BVS implantation with perfect BVS apposition from distal to proximal; G, H, I. OCT images after 6 months with covered apposed BVS struts from distal to proximal; LAD — left anterior descending artery.

\section{Statistical analysis}

Continuous data were summarised as means and standard deviations or as medians and $25^{\text {th }}$ and $75^{\text {th }}$ percentiles, as appropriate. Categorical data are presented as number (percentage). To account for the clustered nature of OCT-data, multilevel regression analyses on lesion level, cross-section level and strut level were realised [13, 14, 27]. For intra-group analysis within each group, an analysis of variance was performed. A p-value $<0.05$ was considered to be statistically significant and all analyses were two-tailed. Intra-observer and interobserver reproducibility was assessed using the in- traclass correlation coefficient. Statistical analysis was performed using GraphPad Prism, version 6 (GraphPad Software, Inc., San Diego, CA, USA).

\section{Results}

\section{Patient baseline characteristics}

A total of 29 patients with 31 lesions and 40 BVSs were analyzed. Figure 1 is depicting the flow chart of the registry. Table 1 summarizes baseline patient characteristics and procedural details. No differences were found between the groups. 
Table 1. Patient baseline characteristics and procedural data.

\begin{tabular}{|c|c|c|c|c|}
\hline Characteristics & $\begin{array}{c}\text { All } \\
(n=29)\end{array}$ & $\begin{array}{l}\text { Group } 1 ; \text { angiography } \\
\text { guiding }(\mathrm{n}=17)\end{array}$ & $\begin{array}{l}\text { Group 2; OCT } \\
\text { guiding }(n=12)\end{array}$ & $\mathbf{P}$ \\
\hline \multicolumn{5}{|l|}{ Clinical features } \\
\hline Age [years] & $56.6 \pm 9.1$ & $53.2 \pm 7.3$ & $61.4 \pm 9.5$ & 0.168 \\
\hline Male sex & $23(79.3 \%)$ & $15(88.2 \%)$ & $8(66.7 \%)$ & 0.198 \\
\hline Obesity & $7(24.1 \%)$ & $4(23.5 \%)$ & $3(25.0 \%)$ & 0.999 \\
\hline Hypertension & $20(69.0 \%)$ & $11(64.7 \%)$ & $9(75.0 \%)$ & 0.694 \\
\hline Hyperlipidemia & $16(55.2 \%)$ & $10(58.8 \%)$ & $6(50.0 \%)$ & 0.927 \\
\hline Diabetes mellitus type II & $7(24.1 \%)$ & $2(11.8 \%)$ & $5(41.7 \%)$ & 0.092 \\
\hline Smoking & $23(79.3 \%)$ & $15(88.2 \%)$ & $8(66.7 \%)$ & 0.198 \\
\hline Prior PCl & $12(41.4 \%)$ & $7(41.2 \%)$ & $5(41.7 \%)$ & 0.999 \\
\hline Prior myocardial infarction & $3(10.3 \%)$ & $1(5.9 \%)$ & $2(16.7 \%)$ & 0.553 \\
\hline Prior CABG & $0(0 \%)$ & $0(0 \%)$ & $0(0 \%)$ & 0.999 \\
\hline Multivessel disease & $20(69.0 \%)$ & $12(70.6 \%)$ & $8(66.7 \%)$ & 0.999 \\
\hline \multicolumn{5}{|l|}{ Clinical presentation at baseline } \\
\hline Stable angina pectoris & $3(10.3 \%)$ & $3(17.7 \%)$ & $0(0 \%)$ & 0.246 \\
\hline Unstable angina pectoris & $18(62.1 \%)$ & $9(52.9 \%)$ & $9(75.0 \%)$ & 0.273 \\
\hline NSTE-ACS & $3(10.3 \%)$ & $2(11.8 \%)$ & $1(8.3 \%)$ & 0.999 \\
\hline STEMI & $5(17.2 \%)$ & $3(17.7 \%)$ & $2(16.7 \%)$ & 0.999 \\
\hline \multicolumn{5}{|l|}{ Treatment } \\
\hline Number of treated lesions & 33 & 19 & 14 & \\
\hline Left anterior descending artery & $19(57.6 \%)$ & $9(47.4 \%)$ & $10(71.4 \%)$ & 0.305 \\
\hline Left circumflex artery & $6(18.2 \%)$ & $3(15.8 \%)$ & $3(21.4 \%)$ & 0.999 \\
\hline Right coronary artery & $8(24.2 \%)$ & $7(36.8 \%)$ & $1(7.1 \%)$ & 0.098 \\
\hline Chronic total occlusions & $3(10.3 \%)$ & $1(5.9 \%)$ & $2(16.7 \%)$ & 0.553 \\
\hline Lesion type $A$ & $3(9.1 \%)$ & $2(10.5 \%)$ & $1(7.1 \%)$ & 0.738 \\
\hline Lesion type B1 & $7(21.2 \%)$ & $5(26.3 \%)$ & $2(14.3 \%)$ & 0.403 \\
\hline Lesion type B2 & $10(30.3 \%)$ & $6(31.6 \%)$ & $4(28.6 \%)$ & 0.853 \\
\hline Lesion type C & $13(39.4 \%)$ & $6(31.6 \%)$ & $7(50 \%)$ & 0.284 \\
\hline BVS/lesion & $1(1.1 \%)$ & $1(1.1 \%)$ & $1(1.1 \%)$ & 0.200 \\
\hline Total BVS length [mm] & $18[18,28]$ & $18[16.5,28]$ & $28[18,40]$ & 0.013 \\
\hline Mean BVS diameter [mm] & $2.94 \pm 0.39$ & $2.95 \pm 0.44$ & $2.92 \pm 0.31$ & 0.861 \\
\hline BVS under expansion & $10(30.3 \%)$ & $5(26.3 \%)$ & $3(21.4 \%)$ & 0.999 \\
\hline Non-compliant post dilatation & $12 / 33(36.4 \%)$ & $19(100 \%)$ & $3(21.4 \%)$ & 0.036 \\
\hline \multicolumn{5}{|l|}{ Drug treatment at discharge } \\
\hline Beta-blocker & $28(96.6 \%)$ & $17(100 \%)$ & $11(91.7 \%)$ & 0.414 \\
\hline ACE/AT1-inhibitors & $28(96.6 \%)$ & $16(94.1 \%)$ & $12(100 \%)$ & 0.999 \\
\hline Calcium antagonists & $4(13.8 \%)$ & $2(11.8 \%)$ & $2(16.7 \%)$ & 0.999 \\
\hline Statins & $29(100 \%)$ & $17(100 \%)$ & $12(100 \%)$ & 0.999 \\
\hline Diuretics & $4(13.8 \%)$ & $2(11.8 \%)$ & $2(16.7 \%)$ & 0.999 \\
\hline Acetylsalicylic acid & $29(100 \%)$ & $17(100 \%)$ & $12(100 \%)$ & 0.999 \\
\hline P2Y12-Inhibitors & $29(100 \%)$ & $17(100 \%)$ & $12(100 \%)$ & 0.999 \\
\hline
\end{tabular}

Values are shown as standard deviations, number (percentage) or medians and $25^{\text {th }}$ and $75^{\text {th }}$ percentiles, as appropriate. The lesion type assessments were performed according to latest ACC/AHA definitions; ACE — angiotensin converting enzyme, AT1 - angiotensin 1; BVS - bioresorbable-vascular-scaffolds; CABG - coronary artery bypass grafting; NSTE-ACS - non-ST elevation-acute coronary syndrome OCT - optical coherence tomography; $\mathrm{PCl}$ - percutaneous coronary intervention; STEMI — ST-segment elevation myocardial infarction

\section{Procedural characteristics}

Lesion preparation using predilation was performed in all patients. In the first 17 consecutive patients (19 lesions) no OCT-based pre-interventional sizing was conducted. Only angiography was used to determine success after BVS-implantation. 
Angiography identified BVS-underexpansion in $5 / 19(26.3 \%)$ lesions. In one of these patients an additional outflow dissection was identified. As recommended by the manufacturer all 19/19 (100\%) BVS received an optimisation using non-compliant balloons. After angiographic success no further imaging was performed. In another 12 patients (14 lesions) OCT-based pre-interventional lesion evaluation and sizing was conducted. Qualitative lesion evaluation found plaque rupture in $4 / 14$ lesions (28.6\%). Concerning plaque composition $7 / 14(50 \%)$ lesions showed predominate lipidrich plaque, $4 / 14$ (28.6\%) fibrous plaque and 3/14 (21.4\%) fibroatheroma. Calcification was observed in $4 / 14(28.6 \%)$ lesions. No thrombus formation was detected. Lesion preparation using semicompliant balloons was performed in all lesions. Angiography identified BVS-underexpansion in 5/14 (35.7\%) lesions and BVS-optimisation using non-compliant balloons was performed. No dissection was identified. After angiographic success an additional OCT-analysis was performed (Fig. 2). OCT detected no tissue prolapse or dissection, yet in $3 / 14(21.4 \%)$ of lesions a BVS-underexpansion $(1 / 14,7.1 \%)$ or malapposition $(2 / 14,14.2 \%)$ was observed and further BVS-optimisation was performed as described above.

\section{OCT-analyses}

Neither at lesion level, cross-section level or strut level were any differences found concerning coverage or apposition between the groups (Table 2). The qualitative assessment was highly reproducible and comparable to findings of other groups: the intra-observer and inter-observer reproducibility $\left(\mathrm{R}^{2}\right)$ were 0.86 and 0.83 , respectively [28]. Mean neointimal area was significantly higher in the angio-guided group.

\section{Clinical follow-up}

Patient clinical follow-up is shown in Table 3. Due to two patients (\#1/\#2) with BVS-thrombosis there were two target-lesion failure in group 1 and none in group 2. ST-segment elevation myocardial infarction (STEMI) due to BVS-thrombosis occurred after 9 months in patient \# 1 while the patient was on dual antiplatelet therapy (DAPT) with acetylsalicylic acid and clopidogrel. The patient was judged to be drug-compliant by the treating physician. Retrospectively, the OCT-analysis at 6-months showed no strut uncoverage or malapposition. The reason for BVS-thrombosis therefore remains elusive in this patient. The patient survived the STEMI with a left ventricular ejection fraction of $39 \%$.
Patient \#2 experienced a BVS-thrombosis with STEMI 18 months after EE-BVS-implantation. In retrospect, OCT-analysis at 6-months in patient \#2 showed partial uncoverage and malapposition of the EE-BVS (23.6\% uncovered apposed struts and $1.9 \%$ uncovered malapposed struts). As the patient had no symptoms of angina and the angiographic picture was unremarkable the decision was made not to perform any treatment based on experience with current generation DES. DAPT was prescribed for a total of 12 months. 18 months after EE-BVS-implantation the patient was readmitted with STEMI due to acute BVS-thrombosis. OCT at this time showed insufficient wall apposition in the distal part of the BVS with subsequent incomplete coverage with neointimal tissue as potential cause for the BVS-thrombosis (Fig. 3) [29]. The patient survived the STEMI with a normal ejection fraction.

\section{Discussion}

This registry describes unremarkable OCT-data at 6-month follow-up of EE-BVS treated patients. Scaffold struts had neointima coverage and strut malapposition rates similar to current generation DES [13]. As BVS have the same everolimus coating as EE-DES, this finding comes as no surprise. Yet the latest data found EE-BVS to be associated with a higher risk of BVS-thrombosis compared to EE-DES [7]. In detail the ABSORB III study found an increase in clinical events at 2-year with EE-BVS compared to EE-DES [3]. Additionally 2 -year results from the Amsterdam Investigator-Initiated Absorb Strategy All-Comers Trial (AIDA) showed that the use of EE-BVS is associated with an increased risk of BVS-thrombosis and of target-vessel MI, compared with patients who received an EE-DES [5]. These findings have led to a warning letter to physicians by the Food and Drug Administration and a stop to routine implants. The future of ABSORB technology is therefore quite uncertain at the moment.

The causes of BVS-thrombosis have yet to be fully elucidated [8]. A recent meta-analysis focusing on possible mechanical causes of BVSthrombosis utilizing intracoronary imaging found malapposition, incomplete lesion coverage, and underdeployment are frequently observed in cases of early BVS-thrombosis, whereas, malapposition, late discontinuity and peri-strut low-intensity area are the predominant factors in late BVS-thrombosis [8]. Repeatedly improved implantation techniques has been hypothesized to allow for better clinical outcomes [7]. 
Table 2. Optical coherence tomography (OCT)-findings.

\begin{tabular}{|c|c|c|c|c|}
\hline Characteristics & $\begin{array}{c}\text { All } \\
(n=29)\end{array}$ & $\begin{array}{l}\text { Group 1; angiography } \\
\text { guiding }(\mathrm{n}=17)\end{array}$ & $\begin{array}{c}\text { Group 2;OCT } \\
\text { guiding }(n=12)\end{array}$ & $\mathbf{P}$ \\
\hline Time to follow-up [days] & $201 \pm 70$ & $197 \pm 82$ & $207 \pm 52$ & 0.478 \\
\hline \multicolumn{5}{|l|}{ Lesion level } \\
\hline Analyzed lesions & 31 & 19 & 14 & - \\
\hline Lesions with uncovered struts & $28(84.9 \%)$ & $16(84.2 \%)$ & $12(85.7 \%)$ & 0.999 \\
\hline Lesions with $\geq 10 \%$ uncovered struts & $0[0,1]$ & $0[0,1]$ & $0.5[0,1]$ & 0.917 \\
\hline Lesions with $\geq 30 \%$ uncovered struts & $2(6.1 \%)$ & $2(10.5 \%)$ & $0(0 \%)$ & 0.496 \\
\hline Lesions with $\geq 5 \%$ malapposed struts & $2(6.1 \%)$ & $2(10.5 \%)$ & $0(0 \%)$ & 0.496 \\
\hline \multicolumn{5}{|l|}{ Cross-section level } \\
\hline Analyzed cross-sections & 805 & 378 & 427 & - \\
\hline Struts analyzed per cross-section & $7.2 \pm 1.2$ & $7.5 \pm 1.3$ & $6.9 \pm 1.0$ & 0.134 \\
\hline Cross-sections with uncovered struts & $36.7 \pm 28.9$ & $33.6 \pm 29.8)$ & $41.0 \pm 25.6$ & 0.507 \\
\hline $\begin{array}{l}\text { Cross-sections with } \geq 10 \% \\
\text { uncovered struts }\end{array}$ & $36.7[7.1,55.6]$ & $31.3[7.0,50.6]$ & $43.4[17.6,56.8]$ & 0.747 \\
\hline $\begin{array}{l}\text { Cross-sections with } \geq 30 \% \\
\text { uncovered struts }\end{array}$ & $3.5[0,19.8]$ & $3.5[0,16.0]$ & $6.9[0,21.6]$ & 0.719 \\
\hline $\begin{array}{l}\text { Cross-sections with } \geq 5 \% \\
\text { malapposed struts }\end{array}$ & $0[0,1.9]$ & $0[0,0]$ & $0[0,3.0]$ & 0.659 \\
\hline Mean vessel diameter $[\mathrm{mm}]$ & $2.6 \pm 0.4$ & $2.6 \pm 0.5$ & $2.6 \pm 0.3$ & 0.854 \\
\hline Mean vessel area $\left[\mathrm{mm}^{2}\right]$ & $5.4 \pm 1.8$ & $5.5 \pm 2.2$ & $5.3 \pm 1.1$ & 0.724 \\
\hline Mean scaffold diameter [mm] & $2.9[2.7,3.0]$ & $2.9[2.7,3.2]$ & $2.8[2.6,3.0]$ & 0.553 \\
\hline Mean scaffold area $\left[\mathrm{mm}^{2}\right]$ & $6.3[5.5,7.0]$ & $6.3[5.7,7.8]$ & $6.5[5.5,6.9]$ & 0.730 \\
\hline Mean neointimal area $\left[\mathrm{mm}^{2}\right]$ & $1.3 \pm 0.3$ & $1.4 \pm 0.3$ & $1.2 \pm 0.2$ & 0.032 \\
\hline Mean area of malapposition $\left[\mathrm{mm}^{2}\right]$ & $0[0,0]$ & $0[0,0]$ & $0[0,0.5]$ & 0.147 \\
\hline \multicolumn{5}{|l|}{ Strut level } \\
\hline Analyzed struts & 5837 & 2790 & 3047 & - \\
\hline Struts analyzed/patient & $160[111,199]$ & $154[107,179]$ & $171[121,250]$ & 0.127 \\
\hline Covered embedded struts & $76.9 \pm 14.9$ & $77.8 \pm 17.4$ & $75.8 \pm 11.1$ & 0.701 \\
\hline Covered protruding struts & $12.0 \pm 9.5$ & $10.8 \pm 10.2$ & $13.5 \pm 8.5$ & 0.655 \\
\hline Uncovered apposed struts & $10.7 \pm 9.2$ & $10.8 \pm 10.0$ & $10.6 \pm 8.2$ & 0.934 \\
\hline Uncovered malapposed struts & $0[0,0]$ & $0[0,0]$ & $0[0,0]$ & 0.779 \\
\hline Neointimal thickness $[\mu \mathrm{m}]$ & $95.7[81,111]$ & $102.2[92,114]$ & $82.3[76,95]$ & 0.176 \\
\hline Strut core area $\left[\mathrm{mm}^{2}\right]$ & $0.04[0.03,0.04]$ & $0.04[0.03,0.04]$ & $0.04[0.03,0.04]$ & 0.999 \\
\hline Non apposed side branch struts & 86 & 36 & 50 & - \\
\hline Excluded struts & 1129 & 550 & 579 & - \\
\hline
\end{tabular}

Values are standard deviations, number (percentage) or medians and $25^{\text {th }}$ and $75^{\text {th }}$ percentiles, as appropriate

In this series, no early BVS-thrombosis was observed. This finding is reassuring proving correct patient selection and improved implantation techniques were rolled out in Germany following early observations of BVS-thrombosis back in 2012 and 2013. However, even OCT-analysis at 6 -months had previously shown subtle differences of stent healing and was detected even with low patient numbers and did not detect any substantial differences between OCT-guided implantation vs. angio-guided implantation, not even as a trend [13]. Even larger patient numbers are therefore was unlikely to reveal a different result. These data confirm the current implantation techniques including lesion preparation, sizing and mandatory post-dilatation with a non-compliant balloon leads to good short-term results. In addition, the absolute values of neointima coverage and strut malapposition are very similar to current generation DES at 6 -months [13]. 
Table 3. Clinical follow-up.

\begin{tabular}{lcccc}
\hline Two-year clinical follow-up & $\begin{array}{c}\text { All } \\
(\mathbf{n}=29)\end{array}$ & $\begin{array}{c}\text { Group 1; angiography } \\
\text { guiding }(\mathbf{n}=\mathbf{1 7})\end{array}$ & $\begin{array}{c}\text { Group 2; OCT } \\
\text { guiding (n= 12) }\end{array}$ & P \\
\hline Major adverse cardiac event & $2(6.9 \%)$ & $2(11.8 \%)$ & $0(0 \%)$ & 0.218 \\
All cause death & $0(0 \%)$ & $0(0 \%)$ & $0(0 \%)$ & 0.999 \\
Unstable angina pectoris & $3(10.3 \%)$ & $2(11.8 \%)$ & $1(8.3 \%)$ & 0.765 \\
Non-ST elevation-acute & $0(0 \%)$ & $0(0 \%)$ & $0(0 \%)$ & 0.999 \\
coronary syndrome & & & $0(0 \%)$ & 0.218 \\
ST elevation myocardial infarction & $2(6.9 \%)$ & $2(11.8 \%)$ & $0(0 \%)$ & 0.999 \\
Target-vessel-failure & $0(0 \%)$ & $0(0 \%)$ & $0(0 \%)$ & 0.999 \\
Target-vessel-revascularization & $0(0 \%)$ & $0(0 \%)$ & $0(0 \%)$ & 0.218 \\
Target-lesion-failure & $2(6.9 \%)$ & $2(11.8 \%)$ & $0(0 \%)$ & 0.218 \\
Target-lesion-revascularization & $2(6.9 \%)$ & $2(11.8 \%)$ & $0(0 \%)$ & 0.999 \\
In-stent restenosis & $0(0 \%)$ & $0(0 \%)$ & $0(0 \%)$ & 0.218 \\
Scaffold-thrombosis & $2(6.9 \%)$ & $2(11.8 \%)$ & $0(0 \%)$ & 0.999 \\
Major bleeding event & $0(0 \%)$ & $0(0 \%)$ & $0(0 \%)$ & 0.393 \\
Minor bleeding event & $1(3.4 \%)$ & $1(5.9 \%)$ & $0(0 \%)$ & 0.393 \\
Cerebrovascular event & $1(3.4 \%)$ & $1(5.9 \%)$ & \\
\hline
\end{tabular}

The data are presented as number of events $(n)$ and percentage of total number (\%).

Surprisingly OCT at 6 -months was unable to define patients at risk for BVS-thrombosis based on the characteristics of strut malapposition and/ /or neointima growth. The two patients that developed BVS-thrombosis at 9 and 18-months had BVS-healing patterns not much different from the rest of the cohort. Discontinuation of DAPT is an important cause of BVS-thrombosis [7], yet the patient was deemed to be compliant and DAPT can be stopped as early as 3-months after DES-implantation without any increased risk of stentthrombosis.

The OCT-analyses of the 2 cases of BVS-thrombosis were inconsistent. While the first patient had a really unremarkable finding of BVS-healing with almost complete coverage at 6 -months, the second patient had malapposed struts partially covered with neointima at the distal end due to an enlargement of the vessel at that particular site. This is seen regularly with current generation DES and is left untreated without consequences [13]. Apparently BVS is less forgiving in this instance yet treatment options are limited if the vessel has various diameters like in this case; the only available option is to prolong DAPT beyond 1 year and most likely until the BVS is completely resorbed which would result in DAPT to be necessary for 3 years. A recent study found no case of very late BVS-thrombosis in patients who continued on DAPT for $>18$ months [30]. Although prolongation of DAPT may prevent BVS-thrombosis, the rate of bleeding events are a matter of concern.

So apparently, improved implantation techniques are unlikely to resolve the issues around BVS late clinical events. Another speculation would be that the BVS-polylactite material may have a late prothrombotic or platelet activation property during resorbing which is not sufficiently understood in the human environment. While there are no such data available the observation from this small cohort, as well as from the recently presented AIDA trial which had a much larger cohort of patients, it was also unable to link implantation technique or any other variable to late BVS-thrombosis suggests other factors could be involved than those currently under discussion [5].

The 3-year data of ABSORB-China and ABSORB-Japan found no increased rate of BVS-thrombosis. An optimal implantation technique was suggested to be responsible for these findings $[31,32]$. Yet the AIDA trial did not support this hypothesis [5]. Aggressive post-dilation may trigger endothelial growth. While all angiography-guided BVS were postdilated, the OCT-guided group only received postdilatation in $21.4 \%$ of cases. In this context it is quite a striking follow-up, OCT found increased neointimal growth reaching a similar thickness compared to data observed with DES in the angio-guided group which is possibly linked to aggressive post-dilation [13]. 


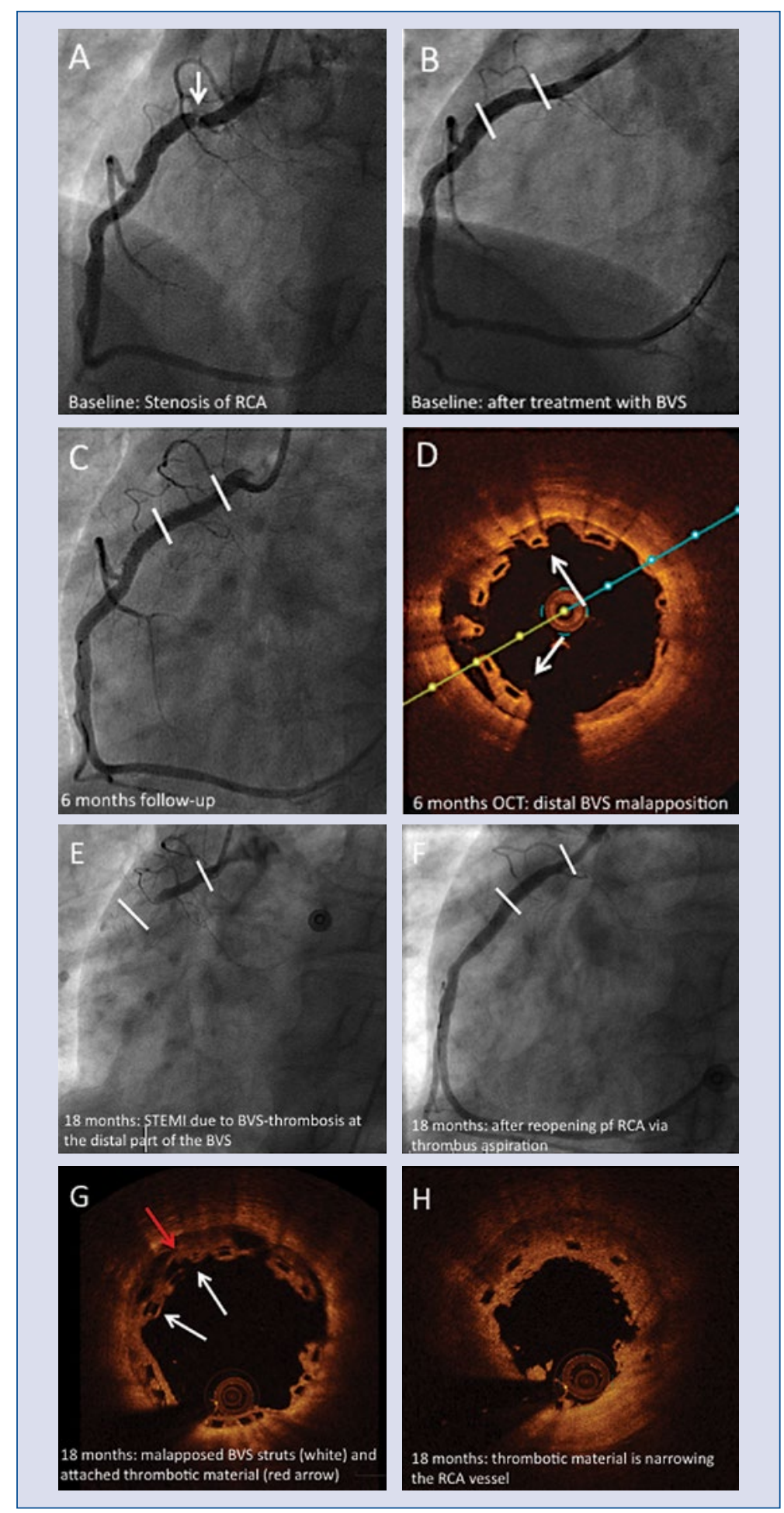

Figure 3. ST-elevation myocardial infarction (STEMI) due to bioresorbable vascular scaffold (BVS)-thrombosis: Angiographies and optical coherence tomography (OCT)-images; A. Baseline coronary angiography with significant stenosis of the proximal right coronary artery (RCA) resulting in BVS implantation; B. Angiography after implantation of a BVS (Absorb $3.5 \times 28 \mathrm{~mm}$, BVS is marked by white bars); C. Angiography at 6 months follow-up; D. OCT of the distal BVS at 6 months follow-up. Please note the insufficient wall apposition and coverage (white arrows); E. Angiography showing acute BVS-thrombosis of the RCA 18 months after implantation (scaffold area is marked by white bars); F. Angiography after reopening of RCA via thrombus aspiration; G. OCT of the distal BVS at the time of BVS thrombosis showing thrombus material attached to the struts and malapposition and coverage as a potential reason for thrombosis (white arrows marks malapposed uncovered struts, red arrow shows thrombus material attached to the struts); H. OCT of the distal BVS with thrombus material which is narrowing the RCA. 
Lesion preparation and post-dilatation with non-compliant balloons has been suggested to improve EE-BVS implantation results [7]. Mandatory post-dilatation was thought to improve implantation outcomes; the OCT-guided data presented here find OCT-guided intervention to lead to comparably good results. Vice versa, angio-guided implantation with mandator post-dilatation has similar results than OCT-guided BVS-implantation. Yet this optimization appears not to prevent BVS-thrombosis. The reasons for this are unclear and apparently needs to be identified prior to further routine use of EE-BVS. The fact that BVS-thrombosis did occur despite BVS-coverage similar to EE-DES leads to the hypothesis that either strut thickness or the BVS-material could be the issue leading to these late events. The issue that the underlying material and resorption may activate platelet adhesion should be investigated and addressed including other materials like magnesium, which should be further studied.

\section{Limitations of the study}

The fact that no randomization was performed is limiting in the conclusions reached. A further limitation is the limited number of patients and the differring sample size of the two groups. The number of patients is certainly too small to draw definitive conclusions about clinical outcomes, yet OCT-assessment of BVS-apposition and coverage correlates to clinical outcomes [12-15].

\section{Conclusions}

This registry found almost $90 \%$ of BVS-struts to be covered with neointima at 6 months. Both angiography- and OCT-guided EE-BVS-implantation had favourable 6-month results based on OCT-data. Yet OCT-analyses at 6-months were not able to predict late clinical events as there were in this study with 2 BVS-thrombosis occurring 9 and 18 months following BVS-implantation.

\section{Acknowledgements}

We wish to thank the late Cathrin Riez for her excellent assistance during the whole project.

Conflict of interest: Christian-Hendrik Heeger received travel grants by St. Jude Medical and Biotronik. Karl-Heinz Kuck received research contracts/grants by Medtronic, St. Jude and Boston Scientific as well as consulting fees by St. Jude and Edwards Lifescience. Martin W. Bergmann received travel grants, research grants and speaker honoraria by Medtronic, Biotronik, Abbott and St. Jude Medical. All other authors reported no relationships relevant to the contents of this paper to disclose.

\section{References}

1. Serruys PW, Chevalier B, Dudek D, et al. A bioresorbable everolimus-eluting scaffold versus a metallic everolimus-eluting stent for ischaemic heart disease caused by de-novo native coronary artery lesions (ABSORB II): an interim 1-year analysis of clinical and procedural secondary outcomes from a randomised controlled trial. Lancet. 2015; 385(9962): 43-54, doi: 10.1016/ S0140-6736(14)61455-0, indexed in Pubmed: 25230593.

2. Ellis SG, Kereiakes DJ, Metzger DC, et al. ABSORB III Investigators. Everolimus-Eluting Bioresorbable Scaffolds for Coronary Artery Disease. N Engl J Med. 2015; 373(20): 1905-1915, doi: 10.1056/NEJMoa1509038, indexed in Pubmed: 26457558.

3. Ellis SG: Everolimus-eluting bioresorbable vascular scaffolds in patients with coronary artery disease: ABSORB III trial 2-year results. Presented at: ACC 2017. Washington, DC, March 18, 2017.

4. Stone GW, Gao R, Kimura T, et al. 1-year outcomes with the Absorb bioresorbable scaffold in patients with coronary artery disease: a patient-level, pooled meta-analysis. Lancet. 2016; 387(10025): 1277-1289, doi: 10.1016/S0140-6736(15)01039-9, indexed in Pubmed: 26825231.

5. Wykrzykowska JJ, Kraak RP, Hofma J, et al. Bioresorbable Scaffolds versus Metallic Stents in Routine PCI. N Engl J Med. 2017; 376(24): 2319-2328, doi: 10.1056/NEJMoa1614954, indexed in Pubmed: 28402237.

6. Tamburino C, Latib A, van Geuns RJ, et al. Contemporary practice and technical aspects in coronary intervention with bioresorbable scaffolds: a European perspective. EuroIntervention. 2015; 11(1): 45-52, doi: 10.4244/EIJY15M01_05, indexed in Pubmed: 25599676.

7. Colombo A, Azzalini L. Optimal implantation is the way to prevent scaffold thrombosis: a hypothesis to be tested. EuroIntervention. 2017; 13(2): e142-e144, doi: 10.4244/EIJV13I2A19, indexed in Pubmed: 28512067.

8. Sotomi Y, Suwannasom P, Serruys PW, et al. Possible mechanical causes of scaffold thrombosis: insights from case reports with intracoronary imaging. EuroIntervention. 2017; 12(14): 1747-1756, doi: 10.4244/EIJ-D-16-00471, indexed in Pubmed: 27773862.

9. Serruys PW, Chevalier B, Sotomi Y, et al. Comparison of an everolimus-eluting bioresorbable scaffold with an everolimuseluting metallic stent for the treatment of coronary artery stenosis (ABSORB II): a 3 year, randomised, controlled, single-blind, multicentre clinical trial. Lancet. 2016; 388(10059): 2479-2491, doi: 10.1016/S0140-6736(16)32050-5, indexed in Pubmed: 27806897.

10. Allahwala UK, Cockburn JA, Shaw E, et al. Clinical utility of optical coherence tomography (OCT) in the optimisation of Absorb bioresorbable vascular scaffold deployment during percutaneous coronary intervention. EuroIntervention. 2015; 10(10): 1154-1159, doi: 10.4244/EIJV10I10A190, indexed in Pubmed: 24647105.

11. Prati F, Di Vito L, Biondi-Zoccai G, et al. Angiography alone versus angiography plus optical coherence tomography to guide decision-making during percutaneous coronary intervention: the 
Centro per la Lotta contro l'Infarto-Optimisation of Percutaneous Coronary Intervention (CLI-OPCI) study. EuroIntervention. 2012; 8(7): 823-829, doi: 10.4244/EIJV8I7A125, indexed in Pubmed: 23034247.

12. Guagliumi G, Musumeci G, Sirbu V, et al. ODESSA Trial Investigators. Optical coherence tomography assessment of in vivo vascular response after implantation of overlapping baremetal and drug-eluting stents. JACC Cardiovasc Interv. 2010; 3(5): 531-539, doi: 10.1016/j.jcin.2010.02.008, indexed in Pubmed: 20488410.

13. Heeger C-H, Fenski M, Hildebrand L, et al. Optical coherence tomography analysis of neointimal tissue in drug-eluting stents with biodegradable and durable polymer coatings: the ALSTEROCT registry. AsiaIntervention. 2017; 3: 41-48.

14. Heeger $\mathrm{CH}$, Busjahn A, Hildebrand L, et al. Delayed coverage of drug-eluting stents after interventional revascularisation of chronic total occlusions assessed by optical coherence tomography: the ALSTER-OCT-CTO registry. EuroIntervention. 2016; 11(9): 1004-1012, doi: 10.4244/EIJY14M10_01, indexed in Pubmed: 25287264.

15. Malle C, Tada T, Steigerwald K, et al. Tissue characterization after drug-eluting stent implantation using optical coherence tomography. Arterioscler Thromb Vasc Biol. 2013; 33(6): 1376-1383, doi: 10.1161/ATVBAHA.113.301227, indexed in Pubmed: 23539216.

16. Kochman J, Tomaniak M, Pietrasik A, et al. Bioresorbable everolimus-eluting vascular scaffold in patients with ST-segment elevation myocardial infarction: Optical coherence tomography evaluation and clinical outcomes. Cardiol J. 2015; 22(3): 315-322, doi: 10.5603/CJ.a2014.0090, indexed in Pubmed: 25428734.

17. Sakakura K, Ako J, Wada H, et al. ACC/AHA classification of coronary lesions reflects medical resource use in current percutaneous coronary interventions. Catheter Cardiovasc Interv. 2012; 80(3): 370-376, doi: 10.1002/ccd.23270, indexed in Pubmed: 21805596.

18. Windecker S, Kolh P, Alfonso F, et al. 2014 ESC/EACTS guidelines on myocardial revascularization. EuroIntervention. 2015; 10(9): 1024-1094, doi: 10.4244/EIJY14M09_01, indexed in Pubmed: 25187201.

19. Serruys PW, Onuma Y, Ormiston JA, et al. Evaluation of the second generation of a bioresorbable everolimus drug-eluting vascular scaffold for treatment of de novo coronary artery stenosis: six-month clinical and imaging outcomes. Circulation. 2010; 122(22): 2301-2312, doi: 10.1161/CIRCULATIONAHA.110.970772, indexed in Pubmed: 21098436.

20. Tearney GJ, Regar E, Akasaka T, et al. International Working Group for Intravascular Optical Coherence Tomography (IWGIVOCT). Consensus standards for acquisition, measurement, and reporting of intravascular optical coherence tomography studies: a report from the International Working Group for Intravascular Optical Coherence Tomography Standardization and Validation. J Am Coll Cardiol. 2012; 59(12): 1058-1072, doi: 10.1016/j. jacc.2011.09.079, indexed in Pubmed: 22421299.

21. Prati F, Guagliumi G, Mintz GS, et al. Expert's OCT Review Document. Expert review document part 2: methodology, terminology and clinical applications of optical coherence tomography for the assessment of interventional procedures. Eur Heart J. 2012; 33(20): 2513-2520, doi: 10.1093/eurheartj/ehs095, indexed in Pubmed: 22653335.
22. Ormiston JA, Serruys PW, Onuma Y, et al. First serial assessment at 6 months and 2 years of the second generation of absorb everolimus-eluting bioresorbable vascular scaffold: a multi-imaging modality study. Circ Cardiovasc Interv. 2012; 5(5): 620-632, doi: $10.1161 /$ CIRCINTERVENTIONS.112.971549, indexed in Pubmed: 23048057.

23. Serruys PW, Onuma Y, Dudek D, et al. Evaluation of the second generation of a bioresorbable everolimus-eluting vascular scaffold for the treatment of de novo coronary artery stenosis: 12-month clinical and imaging outcomes. J Am Coll Cardiol. 2011; 58(15): 1578-1588, doi: 10.1016/j.jacc.2011.05.050, indexed in Pubmed: 21958884.

24. Pilgrim T, Heg D, Roffi M, et al. Ultrathin strut biodegradable polymer sirolimus-eluting stent versus durable polymer everolimus-eluting stent for percutaneous coronary revascularisation (BIOSCIENCE): a randomised, single-blind, non-inferiority trial. Lancet. 2014; 384(9960): 2111-2122, doi: 10.1016/S01406736(14)61038-2, indexed in Pubmed: 25189359.

25. Waltenberger J, Brachmann J, van der Heyden J, et al. BIOFLOW-III Investigators. Real-world experience with a novel biodegradable polymer sirolimus-eluting stent: twelve-month results of the BIOFLOW-III registry. EuroIntervention. 2016; 11(10): 1106-1110, doi: 10.4244/EIJY15M03_08, indexed in Pubmed: 25782184 .

26. Kimura T, Morimoto T, Natsuaki M, et al. RESET Investigators. Comparison of everolimus-eluting and sirolimus-eluting coronary stents: 1-year outcomes from the Randomized Evaluation of Sirolimus-eluting Versus Everolimus-eluting stent Trial (RESET). Circulation. 2012; 126(10): 1225-1236, doi: 10.1161/CIRCULATIONAHA.112.104059, indexed in Pubmed: 22824435.

27. Räber L, Zaugg S, Windecker S, et al. Intricacies in the analysis and interpretation of optical coherence tomography findings. EuroIntervention. 2014; 9(12): 1374-1377, doi: 10.4244/ EIJV9I12A232, indexed in Pubmed: 24755380.

28. Kim BK, Ha J, Mintz GS, et al. Randomised comparison of strut coverage between Nobori biolimus-eluting and sirolimus-eluting stents: an optical coherence tomography analysis. EuroIntervention. 2014; 9(12): 1389-1397, doi: 10.4244/EIJV9I12A236, indexed in Pubmed: 24531309.

29. Meincke F, Spangenberg T, Heeger CH, et al. Very Late Scaffold Thrombosis Due to Insufficient Strut Apposition. JACC Cardiovasc Interv. 2015; 8(13): 1768-1769, doi: 10.1016/j. jcin.2015.06.026, indexed in Pubmed: 26476613.

30. Felix CM, Vlachojannis GJ, IJsselmuiden AJJ, et al. Potentially increased incidence of scaffold thrombosis in patients treated with Absorb BVS who terminated DAPT before 18 months. EuroIntervention. 2017; 13(2): e177-e184, doi: 10.4244/EIJ-D-17-00119, indexed in Pubmed: 28512068.

31. Gao R: Gao R, on behalf of the ABSORB-China Investigators. Randomized comparison of everolimus-eluting bioresorbable vascular scaffolds versus everolimus-eluting metallic stents in patients with coronary artery disease. Presented at: EuroPCR 2017.

32. Kozuma K: Kozuma K, on behalf of the ABSORB-Japan Investigators. ABSORB-Japan: 3-year clinical and angiographic results of a randomized trial evaluating the Absorb bioresorbable vascular scaffold vs metallic DES in de novo native coronary artery lesions. Presented at: EuroPCR 2017. 